\title{
Perancangan Sistem Informasi Persediaan Barang Berbasis Web pada Alzena Hijab Store Banjarmasin
}

\author{
${ }^{1}$ Effan Najwaini*, ${ }^{2}$ Purnama, ${ }^{3}$ Nur Rizki Aulia \\ ${ }^{1,2,3}$ Politeknik Negeri Banjarmasin
}

\author{
Alamat Surat \\ Email: effan@poliban.ac.id* \\ Article History: \\ Received: 30-Oktober-2020; Received in Revised: 5-Nopember-2020; Accepted: 10-Nopember-2020
}

\begin{abstract}
ABSTRAK
Pada era teknologi informasi seperti sekarang ini, efisiensi waktu dan tenaga, serta kemudahan dalam mendapatkan suatu informasi sangatlah dibutuhkan. Dalam sebuah usaha toko kecepatan dalam pengolahan data sangatlah penting. Oleh karena itu, harus ditunjang dengan sarana dan prasarana yang memadai. Pada toko ini masih menggunakan sistem komputer manual dengan mencatat semua data menggunakan aplikasi Microsoft office excel sehingga proses penelusuran laporan barang masuk dan keluar menjadi lama karena melihat sheet by sheet . Sehingga sangat dibutuhkan suatu sistem yang dapat mengatasi masalah tersebut. Pada penelitian ini akan dibuat aplikasi sistem yang mampu memberikan informasi untuk laporan persediaan barang secara cepat dan tepat. Untuk membangun sistem tersebut, maka dapat dilakukan pembuatan aplikasi berbasis web dengan menggunakan framework PHP sebagai kode programnya dan MySQL sebagai basisdatanya. Adapun langkahlangkah penelitiannya meliputi: analisa kebutuhan sistem, desain sistem, pembuatan kode program, pengujian, dan pemeliharaan. Aplikasi sistem informasi yang dibuat dalam penelitian ini memberikan kontribusi yang cukup berarti bagi toko tersebut. Hasil penelitian akan menghasilkan sebuah sistem informasi persediaan barang berbasis website yang memberikan kemudahan dalam mengelola persediaan barang.
\end{abstract}

Kata kunci: sistem informasi; persediaan barang; PHP; MySQL

ABSTRACT

In the era of information technology today, the efficiency of time and energy and ease in obtaining information is needed. In a store business, speed in data processing is critical. Therefore, it must be supported by adequate facilities and infrastructure. In this shop, it still uses a manual computer system by recording all data using the Microsoft office excel application so that the tracking process of incoming and outgoing goods reports takes a long time is because see sheet by sheet. So we need a system that can solve these problems. In this study, a system application will be made to quickly and accurately provide information for inventory reports. Build the system, web-based applications can be made using the PHP framework as the program code and MySQL. The research steps include system requirements analysis, system design, program code creation, testing, and maintenance. Information system applications made in this study provide a significant contribution to the store. The results of this research will produce a website-based inventory information system that makes it easy to manage inventory.

Keywords: information system; inventory; PHP ; MySQL 


\section{PENDAHULUAN}

Kemajuan teknologi informasi pada sekarang ini benar-benar pesat sehingga manusia dalam melakukan setiap pekerjaan selalu membutuhkan komputer untuk mendorong performa dalam memenuhi kebutuhan akan kecepatan dan ketepatan suatu data. Komputer memiliki peranan yang sangat vital dalam pemecahan situasi sulit khususnya dalam pengolahan data, sebab komputer mempunyai kecepatan tingkat ketepatan yang tinggi dalam pemrosesan data sehingga pelaksanaan pengolahan data tidak membutuhkan waktu yang lama dan lebih jitu. Adanya sistem jaringan komputer juga mempermudah proses pengolahan data sehingga data dapat diakses atau ditampilkan secara fleksible tanpa terpaku pada satu perangkat saja.

Sebagian besar toko hijab di Banjarmasin mengelola persediaan barang mereka secara manual, sehingga para pegawai melihat maupun memasukkan banyaknya informasi persediaan barang secara manual melalui catatan dan membutuhkan waktu yang cukup lama. Selain melalui catatan dalam pengelolaan data persediaan barang akan lebih efektif bila memakai sistem komputer yang memadai, dimana persediaan suatu barang akan lebih terorganisir dengan baik. Dengan menggunakan sistem komputer, maka proses pencarian ataupun pengolahan data akan lebih cepat.

Sistem persediaan merupakan suatu cara untuk manajemen material yang berkaitan dengan persediaan. Dalam konteks toko jilbab, sistem persediaan meliputi persediaan stok barang yang akan dijual kepada konsumen. Toko Alzena Hijab Store bergerak dalam bidang penjualan berbagai macam jenis hijab dan pakaian. Toko ini memiliki konsumen yang cukup banyak. Pemasaran yang dilakukan toko ini dilakukan melalui toko fisik (offline) maupun melalui media sosial. Semakin meningkatnya jumlah pelanggan toko maka perlu adanya sistem pencatatan stok barang yang berguna untuk mempercepat proses pencarian data stok maupun proses pencatatan keuangan. Sistem pencatatan yang selama ini dilakukan toko Alzena yaitu dengan mencatat pada aplikasi Spreadsheet dimana memiliki beberapa kelemahan yaitu tidak adanya pembagian hak akses, proses pencatatan yang dilakukan secara offline serta masalah pencarian data. Untuk itu maka perlu dibuat suatu sistem Aplikasi Persediaan Barang berbasis Web Pada Alzena Hijab Store.

\section{METODE}

\subsection{Jenis Penelitian}

Dalam penelitian ini, penulis melihat kondisi objek penelitian dan tujuan penelitian untuk Sistem Informasi Persediaan Barang Berbasis Web Pada Alzena Hijab Store tahapan-tahapan yang penulis lakukan sebagai berikut :

a. Pengumpulan data.

b. Analisa.

c. Perancangan.

d. Penerapan.

Dari uraian diatas penulis menggunakan penelitian terapan (applied research) karena penelitian yang dilakukan langsung di lapangan, dalam situasi dan kondisi riil, dan secara sistematik. Selain itu penelitian terapan merupakan salah satu jenis penelitian yang bertujuan untuk memberikan solusi atas permasalahan tertentu secara praktis. Ciri utama dari penelitian ini adalah tingkat abstraksi yang rendah dan manfaat atau dampaknya dapat dirasakan secara langsung.

\subsection{Lokasi Penelitian}

Alzena Hijab Store ini berlokasi di Jl. S.Parman RT. 19 Banjarmasin, Belitung Utara, Banjarmasin Barat.

\subsection{Sumber Data}

a. Data Primer

Data primer merupakan sumber data yang diperoleh langsung dari sumber asli (tidak melalui media perantara). Data primer dapat berupa hasil observasi terhadap suatu benda (fisik), kejadian atau kegiatan, dan hasil pengujian. 
b. Data Sekunder

Data sekunder adalah data yang diperoleh peneliti dari sumber yang sudah ada. Data sekunder dapat berupa catatan, dokumen atau laporan historis (arsip) yang dipublikasikan dan yang tidak dipublikasikan.

\subsection{Teknik Pengumpulan Data}

Teknik pengumpulan data yang digunakan untuk mendapatkan data primer, yaitu :

\section{Observasi}

Penggunaan teknik observasi langsung memungkinkan bagi peneliti untuk mengumpulkan data dari bagian kasir, Bagian gudang, di Alzena Hijab Store ini untuk mengenai pendataan secara detail. Pengamat hanya mencatat apa yang di dapat dari sumber tersebut sehingga mempunyai informasi yang pasif. Banyak tipe data yang dikumpulkan melalui teknik observasi langsung ini hasilnya lebih akurat dan memerlukan biaya yang relatif lebih ekonomis.

\section{Wawancara}

Wawancara adalah sebuah teknik pengumpulan data dengan melakukan wawancara secara dialog dengan mengajukan berbagai pertanyaan kepada Pemilik, dan pihak lainnya yang terlibat, Kelebihan teknik wawancara melalui tatap muka dari pada melalui telepon atau pun kuesioner memungkinkan untuk mengajukan banyak pertanyaan yang memerlukan waktu yang panjang.

\section{Metode Pengembangan Sistem}

Metode yang digunakan penulis dalam melakukan pengembangan sistem penjualan ini yaitu menggunakan model waterfall. Fase-fase dalam Waterfall Model menurut referensi Pressman:

a. Komunikasi (Communication)

Sebelum memulai pekerjaan yang bersifat teknis, sangat diperlukan adanya komunikasi dengan customer demi memahami dan mencapai tujuan yang ingin dicapai. Hasil dari komunikasi tersebut adalah inisialisasi proyek, seperti menganalisis permasalahan yang dihadapi dan mengumpulkan data-data yang diperlukan, serta membantu mendefinisikan fitur dan fungsi software. Pengumpulan data-data tambahan bisa juga diambil dari jurnal, artikel, dan internet.

b. Perencanaan (Planning)

Tahap berikutnya adalah tahapan perencanaan yang menjelaskan tentang estimasi tugas-tugas teknis yang akan dilakukan, resiko- resiko yang dapat terjadi, sumber daya yang diperlukan dalam membuat sistem, produk kerja yang ingin dihasilkan, penjadwalan kerja yang akan dilaksanakan, dan tracking proses pengerjaan sistem.

c. Analisis \& Desain (Analysis \& Design)

Tahapan ini adalah tahap perancangan dan permodelan arsitektur sistem yang berfokus pada perancangan struktur data, arsitektur software, tampilan interface, dan algoritma program. Tujuannya untuk lebih memahami gambaran besar dari apa yang akan dikerjakan.

d. Pengkodean \& Pengujian (Code \& Test)

Tahapan Construction ini merupakan proses penerjemahan bentuk desain menjadi kode atau bentuk/bahasa yang dapat dibaca oleh mesin. Setelah pengkodean selesai, dilakukan pengujian terhadap sistem dan juga kode yang sudah dibuat. Tujuannya untuk menemukan kesalahan yang mungkin terjadi untuk nantinya diperbaiki.

e. Deployment (Delivery, Support, Feedback)

Tahapan Deployment merupakan tahapan implementasi software ke customer, pemeliharaan software secara berkala, perbaikan software, evaluasi software, dan pengembangan software berdasarkan umpan balik yang diberikan agar sistem dapat tetap berjalan dan berkembang sesuai dengan fungsinya. (Pressman,2015:17).

\section{HASIL DAN PEMBAHASAN}

3.1 Analisis Sistem Lama 


\section{a. Flowchart Sistem Lama}

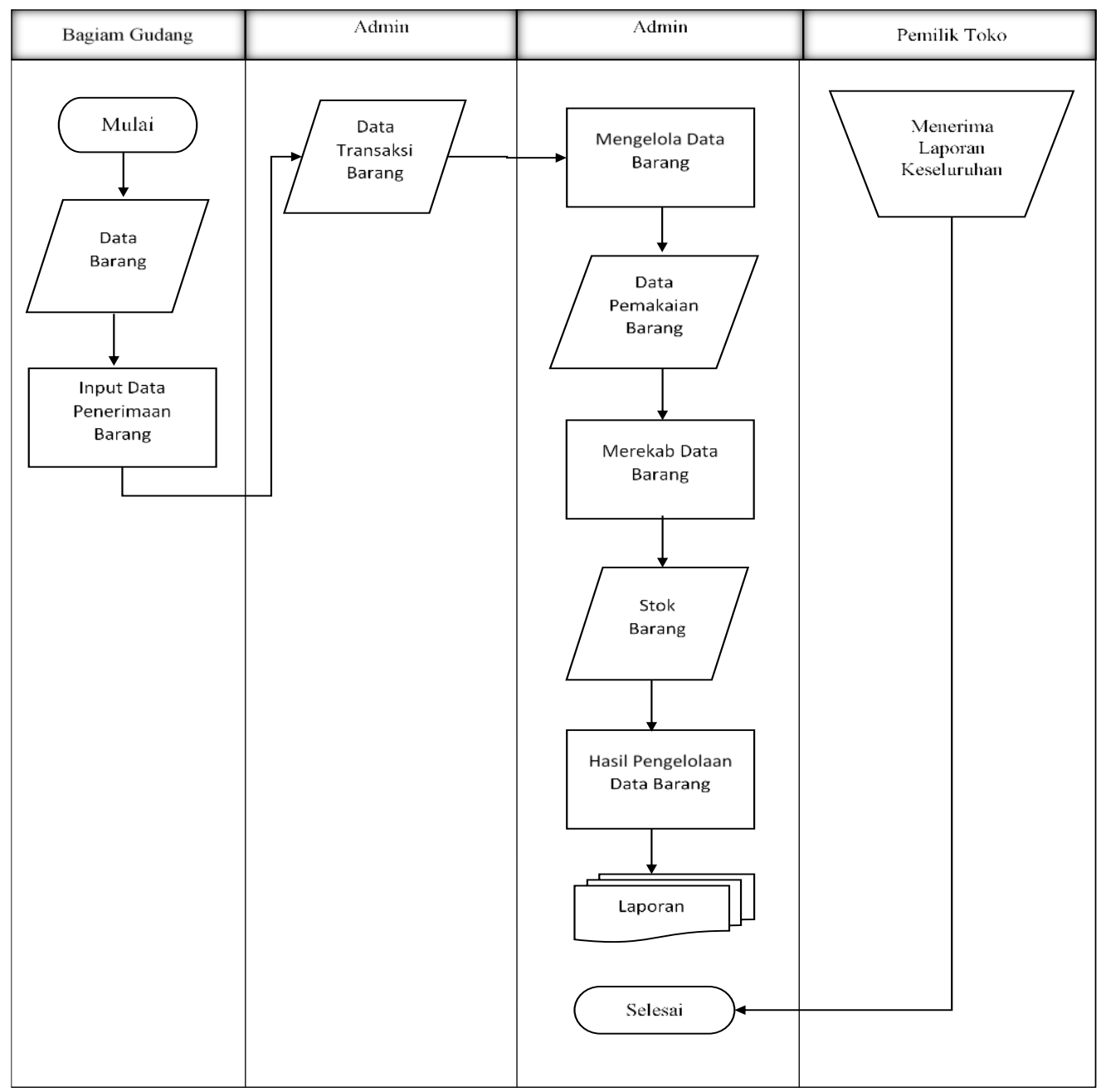

Gambar 1. Flowchart Sistem Lama

\section{b. Analisis PIECES}

i. Analisis Kinerja (Performance)

Tabel 1. Analisis Kinerja

\begin{tabular}{|c|c|}
\hline Sistem Lama & Sistem Baru \\
\hline $\begin{array}{l}\text { Untuk melakukan Proses Pengelolaan } \\
\text { Persediaan Barang pada Alzena Hijab Store } \\
\text { perlu membuka catatan arsip dari buku yang } \\
\text { memerlukan waktu lama. }\end{array}$ & $\begin{array}{l}\text { Dengan adanya Sistem Informasi Persediaan } \\
\text { Barang ini admin dapat melakukan proses } \\
\text { mengelola data barang menjadi cepat dan tepat }\end{array}$ \\
\hline
\end{tabular}

ii. Analisis Informasi (Information)

Tabel 2. Analisis Informasi

\section{Sistem Lama}

Karena informasi masih berupa arsip. Jadi pencarian informasi memerlukan waktu yang cukup lama.

\section{Sistem Baru}

Dengan adanya Sistem ini penyajian informasi dapat secara cepat dan tepat sesuai dengan kebutuhan yang diperlukan. 
iii. Analisis Ekonomi (Economy)

Tabel 3. Analisis Ekonomi

\begin{tabular}{|l|l|}
\hline \multicolumn{1}{|c|}{ Sistem Lama } & \multicolumn{1}{|c|}{ Sistem Baru } \\
\hline $\begin{array}{l}\text { Pemborosan biaya dalam proses pencatatan, dan } \\
\text { yang lainnya, karena apabila terjadi kesalahan } \\
\text { tidak dapat digunakan lagi. }\end{array}$ & $\begin{array}{l}\text { Dengan adanya Sistem Informasi ini akan } \\
\text { menghemat waktu dan biaya untuk penulisan } \\
\text { stok persediaan dan apabila terjadi kesalahan } \\
\text { dapat diedit/diperbaiki. }\end{array}$ \\
\hline
\end{tabular}

iv. Analisis Pengendalian (Control)

Tabel 4. Analisis Pengendalian

\begin{tabular}{|c|c|}
\hline Sistem Lama & Sistem Baru \\
\hline $\begin{array}{l}\text { Tidak adanya proteksi terhadap dokumen } \\
\text { tercetak mengakibatkan orang yang tidak } \\
\text { berkepentingan dapat mengakses. }\end{array}$ & $\begin{array}{l}\text { Dengan adanya sistem yang baru akan lebih } \\
\text { terkendali dan memberikan keamanan informasi } \\
\text { yaitu adanya verifikasi user/ pengguna untuk } \\
\text { mengakses sistem. }\end{array}$ \\
\hline
\end{tabular}

v. Analisis Efisiensi (Effeciency)

Tabel 5. Analisis Efisiensi

\begin{tabular}{|l|l|}
\hline \multicolumn{1}{|c|}{ Sistem Lama } & \multicolumn{1}{c|}{ Sistem Baru } \\
\hline $\begin{array}{l}\text { Pencarian data seperti data barang dan } \\
\text { transaksi barang masih manual sehingga proses } \\
\text { pengolalan data barang kurang efisien. }\end{array}$ & $\begin{array}{l}\text { Dengan adanya sistem informasi ini maka } \\
\text { penggunaan teknologi komputer dapat } \\
\text { meningkatkan kecepatan dan efisiensi tanpa } \\
\text { adanya waktu akses. }\end{array}$ \\
\hline
\end{tabular}

vi. Analisis Pelayanan (Service)

Tabel 6. Analisis Pelayanan

\begin{tabular}{|l|l|}
\hline \multicolumn{1}{|c|}{ Sistem Lama } & \multicolumn{1}{c|}{ Sistem Baru } \\
\hline $\begin{array}{l}\text { Pelayanan informasi yang diperlukan memakan } \\
\text { waktu yang lama. }\end{array}$ & $\begin{array}{l}\text { Waktu yang diperlukan lebih singkat dan cepat } \\
\text { dalam pengelolaan informasi secara sistematis. }\end{array}$ \\
\hline
\end{tabular}

\subsection{Analisis Kebutuhan Sistem}

\section{a. Kebutuhan Fungsional}

\section{Admin / Pegawai}

a. Dapat melihat, menginput dan mengoreksi data persediaan barang.

b. Sistem dapat menyediakan rekapan data persediaan barang yang diinput maupun diedit.

2. Pemilik Alzena Hijab Store

a. Dapat mengelola website secara keseluruhan.

b. Dapat melihat laporan data persediaan barang secara keseluruhan.

c. Dapat menambahkan user baru dan menghapus user.

3. Bagian Gudang

Hanya dapat mengelola data transaksi barang masuk. 


\section{b. Kebutuhan Non Fungsional}

Tabel 7. Perangkat Keras dengan spesifikasi minimum yang digunakan

\begin{tabular}{|l|l|l|}
\hline No. & Perangkat Keras \\
\hline 1 & Prosessor Tipe & Intel Pentium 4 3,2 GHz \\
\hline 2 & Memori & $1 \mathrm{~GB}$ \\
\hline 3 & Kapasitas penyimpanan & $10 \mathrm{~GB}$ \\
\hline
\end{tabular}

Tabel 8. Perangkat Lunak dengan spesifikasi minimum yang digunakan

\begin{tabular}{|l|l|l|}
\hline No. & Perangkat Lunak & \\
\hline 1 & Sistem Operasi & Windows 7 \\
\hline 2 & Server & Xampp 5.6 (PHP 5) \\
\hline 3 & Pengelola Database & PHPMyAdmin dan MySQL \\
\hline 4 & Web Browser & Internet Explore, Mozilla Firefox, Google, dll \\
\hline
\end{tabular}

\subsection{Desain Sistem}

\section{a. Flowchart}

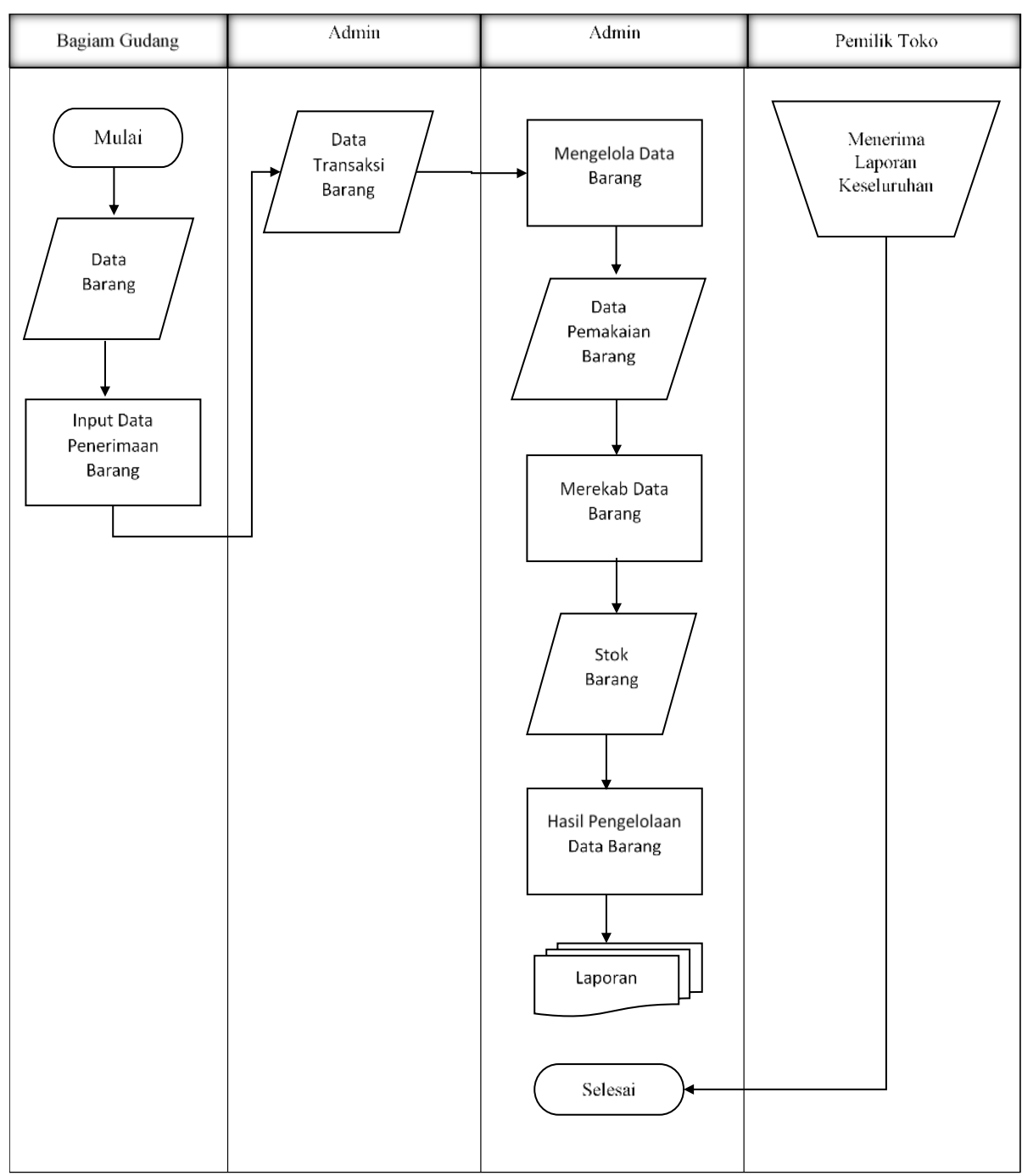

Gambar 2. Flowchart Sistem Baru 


\section{b. Data Flow Diagram}

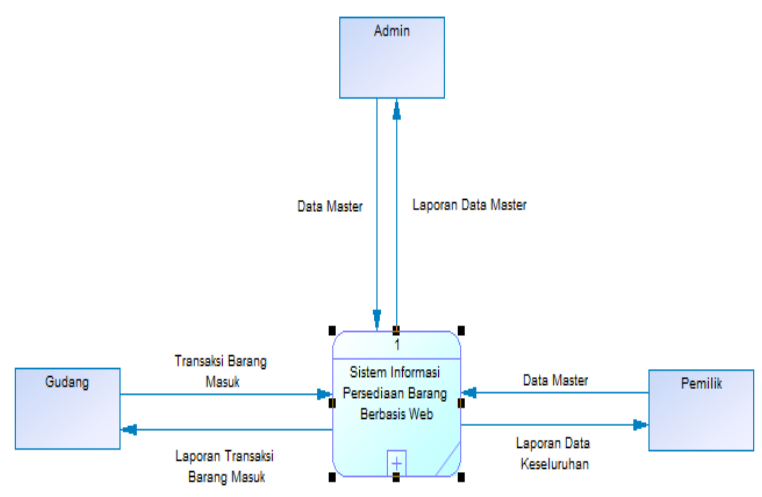

Gambar 3. DFD Level 0

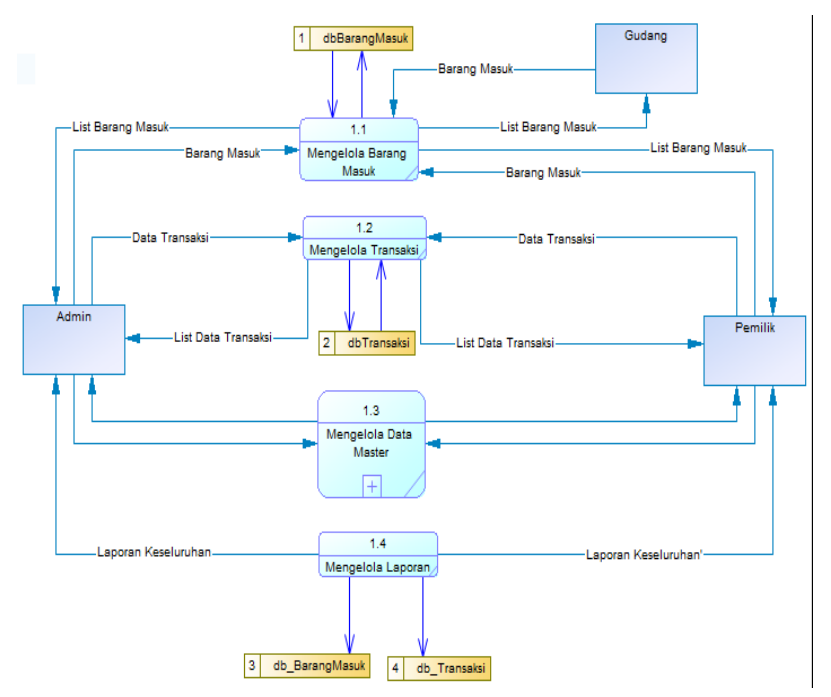

Gambar 4. DFD Level 1

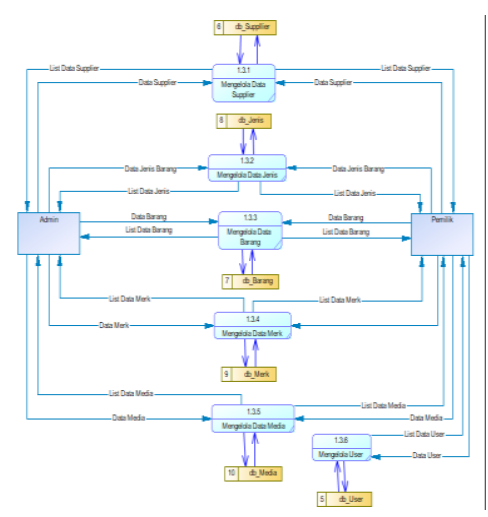

\section{Gambar 5. DFD Level 2}

\section{c. Desain Database (ERD)}

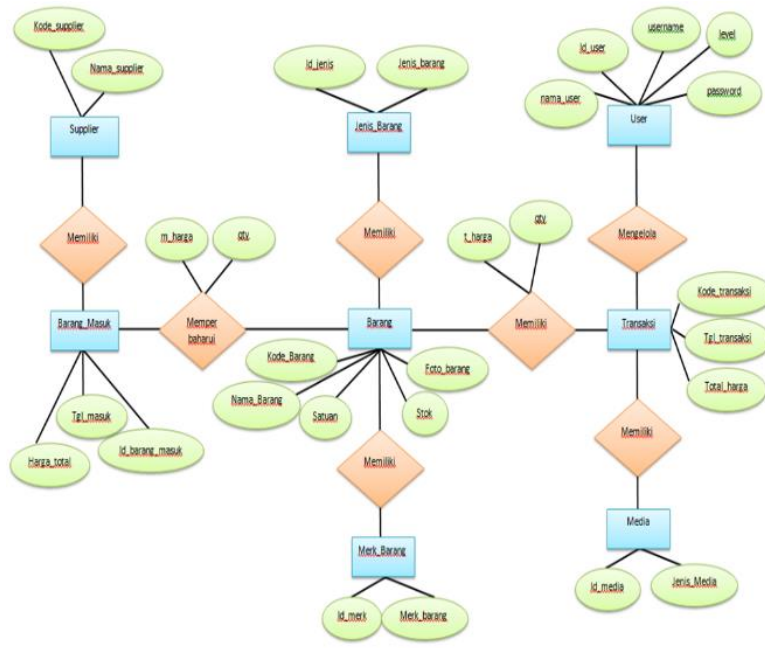

Gambar 6. ERD (Entity Relationship

Diagram)

\section{d. Desain Fisik}

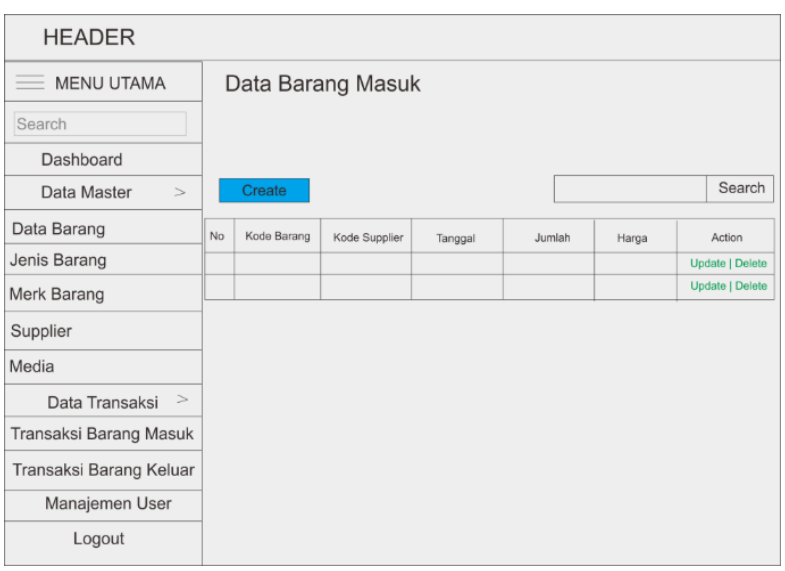

Gambar 7. Desain Antarmuka

\subsection{Pengkodean}

Tahap Pengkodean merupakan tahapan dimana hasil rancangan dan analisa kebutuhan dibuat kedalam bahasa pemograman. Aplikasi dibuat berbasis web dengan menggunakan HTML, CSS dan PHP. Sebagai database menggunakan MariaDB. Implementasi pembuatan program menggunakan framework Codeigniter 3 dimana framework ini merupakan salah satu framework popular yang banyak digunakan dalam pembuatan program. 


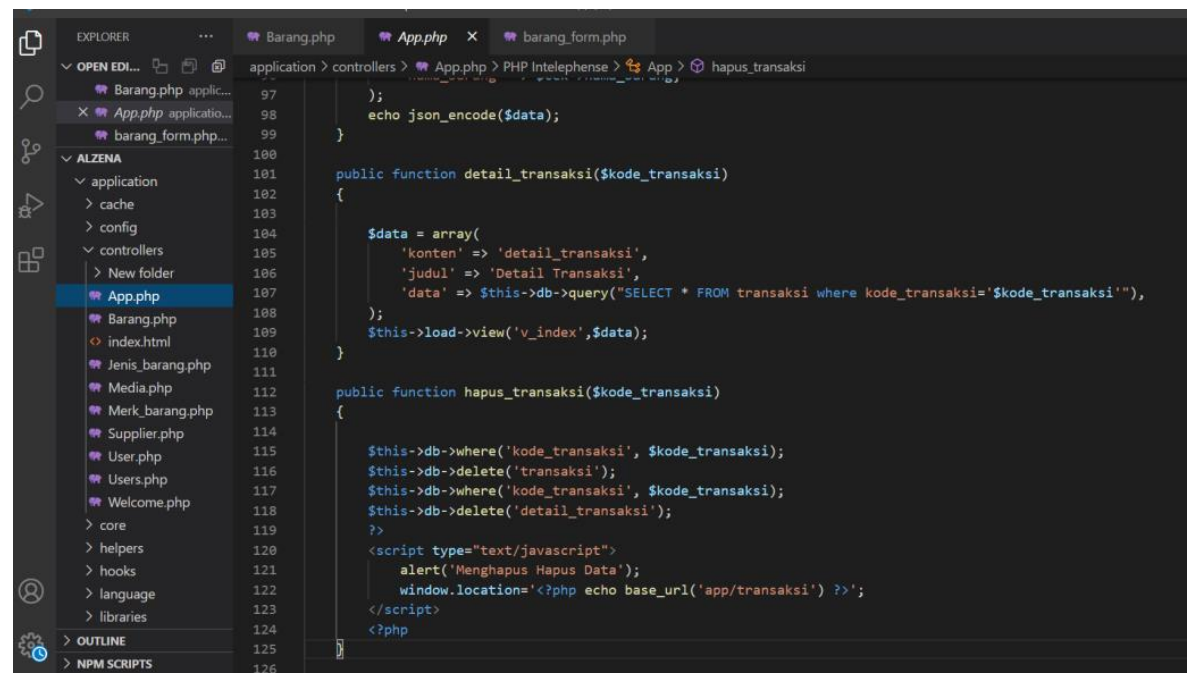

Gambar 8. Implementasi Pembuatan Program

\subsection{Pengujian}

Untuk pengujian fungsional menggunakan teknik Blackbox testing dimana pengujian dilakukan tanpa melalui kode program tetapi hanya melihat secara fungsi setiap modul berjalan dengan normal. Hasil pengujian yang dilakukan sebagai berikut:

\begin{tabular}{|c|c|c|c|c|}
\hline Fungsionalitas & Input & Output yang diharapkan & Pengamatan & Kesimpulan \\
\hline $\begin{array}{l}\text { Keamanan Akses } \\
\text { melalui Form } \\
\text { Login }\end{array}$ & $\begin{array}{l}\text {-Username } \\
\text { Password }\end{array}$ & - Sistem mengenali & $\begin{array}{l}\text {-Sistem mengenali } \\
\text { pengguna }\end{array}$ & $\begin{array}{l}{[\checkmark] \text { Diterima }} \\
{[\text { ] Ditolak }}\end{array}$ \\
\hline \multirow[t]{9}{*}{ Tambah Data } & - Data Barang & - Data masuk ke & - Data masuk ke & {$[\checkmark]$ Diterima } \\
\hline & - Data Jenis Barang & database & database & [ ] Ditolak \\
\hline & - Data Merk Barang & & & \\
\hline & - Data Supplier & & & \\
\hline & -Media & & & \\
\hline & - Data Barang Masuk & & & \\
\hline & - Data Transaksi Barang & & & \\
\hline & Keluar & & & \\
\hline & - Data Manajemen User & & & \\
\hline \multirow[t]{9}{*}{ Ubah Data } & - Data Barang & - Perubahahan data & - Perubahahan data & {$[\checkmark]$ Diterima } \\
\hline & - Data Jenis Barang & fisibel pada antarmuka & fisibel pada antarmuka & [ ] Ditolak \\
\hline & - Data Merk Barang & dan database & dan database & \\
\hline & - Data Supplier & & & \\
\hline & - Data Media & & & \\
\hline & - Data Barang Masuk & & & \\
\hline & - Data Transaksi Barang & & & \\
\hline & Keluar & & & \\
\hline & - Data Manajemen User & & & \\
\hline \multirow[t]{9}{*}{ Hapus Data } & - Data Barang & - Penghapusan data & - Penghapusan data & {$[\checkmark]$ Diterima } \\
\hline & - Data Jenis Barang & fisibel pada antarmuka & fisibel pada antarmuka & [ ] Ditolak \\
\hline & - Data Merk Barang & dan database & dan database & \\
\hline & - Data Supplier & & & \\
\hline & - Data Media & & & \\
\hline & - Data Barang Masuk & & & \\
\hline & - Data Transaksi Barang & & & \\
\hline & Keluar & & & \\
\hline & - Data Manajemen User & & & \\
\hline \multirow[t]{9}{*}{ Pencarian } & - Data Barang & - Pencarian data fleksibel & - Pencarian data fleksibel & {$[\checkmark]$ Diterima } \\
\hline & - Data Jenis Barang & - Mampu mencari & - Mampu mencari & [ ] Ditolak \\
\hline & - Data Merk Barang & berdasarkan kriteria & berdasarkan kriteria & \\
\hline & - Data Supplier & tertentu & tertentu & \\
\hline & - Data Media & - Mampu mencari & - Mampu mencari & \\
\hline & - Data Barang Masuk & berdasarkan range & berdasarkan range & \\
\hline & - Data Transaksi Barang & tertentu & tertentu & \\
\hline & Keluar & & & \\
\hline & - Data Manajemen User & & & \\
\hline \multirow[t]{2}{*}{ Cetak Laporan } & - Data Transaksi Barang & - Cetak Laporan Transaksi & - Cetak Laporan Transaksi & {$[\checkmark]$ Diterima } \\
\hline & Keluar & Barang Keluar & Barang Keluar & [ ] Ditolak \\
\hline
\end{tabular}




\subsection{Deployment}

Setelah dilakukan pengujian, code program siap untuk di-online-kan. Untuk dapat diakses secara online, maka perlu menyewa layanan hosting serta membeli domain sesuai dengan nama toko. Aplikasi yang dibuat dapat diakses secara online melalui alamat http://alzena.store/. Proses selanjutnya setelah deployment yaitu melakukan ujicoba program secara real dengan terlebih dahulu mengajarkan kepada karyawan dan pemilik toko mengenai penggunaan aplikasi yang dibuat.

\section{KESIMPULAN}

Berdasarkan hasil penelitian yang telah dilakukan berkaitan dengan Sistem Informasi Persediaan Barang Berbasis Web Pada Alzena Hijab Store ini, maka dapat diambil kesimpulan sebagai berikut :

a. Pada penilitian ini kami memilih Alzena Hijab Store sebagai objek penelitian, dikarenakan sistemnya belum terkomputerisasi dan masih kurang efektif atau efisien pada bagian persediaan barangnya. Hal ini melatar belakangi penelitian untuk membuat sistem persediaan barangnya.

b. Sistem Informasi Persediaan Barang ini dirancang berdasarkan standarisasi sistem yang baik, melalui beberapa tahapan sebagai berikut :

1) Analisa kelemahan sistem lama.

2) Metode pengembangan sistem

3) (PIECES).

4) Analisa kebutuhan fungsional dan non

5) fungsional pada sistem.

6) Analisa kelayakan sistem.

7) Flowchart sistem lama.

8) Data Flow Diagram (DFD).

9) Desain Sistem.

10) Enhanced Entity Relationship (EER).

11) Struktur database yang terkoneksi.

c. Sistem Informasi Persediaan Barang ini dibangun berbasis web menggunakan framework Codeigniter dan database MySQL.

d. Sistem Informasi Persediaan Barang pada Alzena Hijab Store ini diimplementasi di jaringan internet. Dengan adanya sistem informasi ini, tentunya memudahkan admin mendapatkan informasi yang akurat tentang informasi persediaan barang di Alzena Hijab Store dan menjamin keamanan persediaan dari kemungkinan kesalahan stok dan sebagainya.

\section{DAFTAR PUSTAKA}

Anhar. (2010) . PHP dan Mysql Secara Otodidak. Jakarta:PT TransMedia.

Hakim, Lukmanul. (2010). Membangun Web Berbasis PHP dengan Framework Codeigniter.Yogyakarta:Lokomedia.

Hidayat, Munasasa, Siti. (2017). Implementasi Sistem Informasi Penjualan. Skripsi Minor : Bandung Jayan. (2010). CSS untuk Orang Awam. Palembang : Maxikom

Kadir, A. (2008). Tuntunan Praktis Belajar Database Menggunakan MySQL. Yogyakarta:Andi.

Lubis, Suksesiwaty, Diana, (2010) Perancangan Aplikasi Peminjaman Dan Pengembalian Buku Pada Perpustakaan Politeknik Unggul LP3M Berbasis Desktop, Manajemen Informatika, Politeknik Unggul LP3M, Medan.

Nugroho, Dwi, Hendy, (2018). Pengembangan Sistem Informasi Inventaris Barang Berbasis Website Di SMK Piri 2 Yogyakarta, Tugas Akhir Skripsi, Pendidikan Teknologi Informatika Fakultas Teknik, Universitas Negeri Yogyakarta, Yogyakarta.

Pressman, R.S. (2010). Software Engineering : a practitioner's approach, New York :McGraw-Hill. 
Raharjo, M. (2011). Belajar Pemrograman web. Bandung:Modula.

Rahmawati, (2017). Sistem Informasi Inventory Stok Barang Pada CV. Artha Palembang, Skripsi, Fakultas Sains dan Teknologi Program Studi Sistem Informasi, Universitas Islam Negeri Raden Fatah Palembang, Palembang.

Rosdiana. Rahmawati, Dwi , Eva. Susilowati, Melly, (2015). Sistem Informasi Persediaan Dan Penjualan Barang Berbasis Web Pada Koperasi Kosma 15, Konferensi Nasional Sistem \& Informatika 2015, AMIK Raharja Informatika, Tanggerang.

Sutabri, Tata, (2012). Analisis Sistem Informasi. Yogyakarta :CV Andi OFFSET

Sutanta, Edhy. (2011). Basis Data dalam Tinjauan Konsepsual. Yogyakarta:CV Andi OFFSET

Sujarwadi, Agus. Fatoni, (2019). Sistem Informasi Inventory Barang Berbasis Web, Studi Kasus, Informatika, Universitas Teknologi Yogyakarta, Yogyakarta.

Wild, John J., K. R. Subramanyam, dan Robert F. Halsey. (2004). Financial Statement Analysis. The McGraw-Hill Companies Inc., diterjemahkan oleh Yanivi S. Bachtiar dan S. Nurwahyu Harahap. 2005. Analisis Laporan Keuangan. Jakarta: Salemba Empat 